\title{
Tribbles 3 Regulates the Fibrosis Cytokine TGF- $\beta 1$ through ERK1/2-MAPK Signaling Pathway in Diabetic Nephropathy
}

\author{
Luwei Zhang, ${ }^{1}$ Jinhang Zhang, ${ }^{1}$ Xinnong Liu, ${ }^{2}$ Shengli Liu, ${ }^{1}$ and Jun Tian ${ }^{1}$ \\ ${ }^{1}$ Department of Hemodialysis, Qilu Hospital, Shandong University, Jinan 250012, China \\ ${ }^{2}$ General Department, Qilu Hospital, Shandong University, Jinan 250012, China \\ Correspondence should be addressed to Jun Tian; juntianqlyy@gmail.com
}

Received 18 March 2014; Revised 21 May 2014; Accepted 3 June 2014; Published 16 July 2014

Academic Editor: Joseph Fomusi Ndisang

Copyright (C) 2014 Luwei Zhang et al. This is an open access article distributed under the Creative Commons Attribution License, which permits unrestricted use, distribution, and reproduction in any medium, provided the original work is properly cited.

\begin{abstract}
To reveal the expression and possible role of tribbles homolog 3 (TRB3) in the incidence of type 2 diabetic nephropathy, we used immunohistochemistry, real-time quantitative PCR, western blot analysis, and enzyme-linked immunosorbent assay (ELISA) to study the expression of TRB3, extracellular signal-regulated kinase $1 / 2$ mitogen-activated protein kinase (ERK1/2 MAPK), transforming growth factor $\beta 1$ (TGF- $\beta 1$ ), and collagen type IV in kidneys of $\mathrm{db} / \mathrm{db}$ diabetic mice and in murine renal mesangial cells stimulated with high glucose. The expression of TRB3, TGF- $\beta 1$, and collagen type IV was increased in kidneys of $\mathrm{db} / \mathrm{db}$ diabetic mice. TGF- $\beta 1$ and collagen type IV regulated by high glucose through ERK1/2 MAPK were downregulated by silencing TRB3 in renal mesangial cells. TRB3 may be involved in diabetic nephropathy by regulating the fibrosis cytokine TGF- $\beta 1$ and collagen type IV through the ERK1/2 MAPK signaling pathway.
\end{abstract}

\section{Introduction}

Diabetic nephropathy (DN) is an important diabetic microvascular complication and the major cause of disability and death. Morbidity and mortality with the disease are increasing every year [1]. DN is characterized by albuminuria, glomerular hypertrophy, and progressive accumulation of glomerular matrix, culminating in glomerulosclerosis, tubulointerstitial fibrosis, and progressive loss of renal function $[2,3]$.

Many studies have confirmed that glomerular sclerosis and interstitial fibrosis are the main pathologic characteristics in DN, especially in the midanaphase of DN. Deposition of extracellular matrix (ECM) such as collagens and fibronectin [4] regulated by transforming growth factor $\beta 1$ (TGF- $\beta 1$ ) is the core mechanism of glomerular sclerosis and interstitial fibrosis. The mesangial cells play important roles in $\mathrm{DN}$, being responsible for the accumulation of ECM and mesangial expansion [5]. TGF- $\beta 1$ is the core cytokine leading to the synthesis of ECM, which is responsible for mesangial fibrosis and hypertrophy under diabetic conditions [6]. The major components of the ECM proteins collagen types I-IV and their synthesis and immoderate deposition are consistently observed in multifarious renal disease processes affecting humans and experimental animals $[7,8]$.

Tribbles homolog 3 (TRB3) is an important member of the tribbles family. Combined with unphosphorylated Akt, TRB3 can prevent Akt activity and negatively regulate the insulin signaling pathway [9]. TRB3 and its gene polymorphism are associated with insulin resistance, a vital pathophysiologic characteristic of type 2 diabetes. TRB3 also serves as a scaffold protein and regulates the activation of the three classes of mitogen-activated protein kinases (MAPKs) [10]. As a member of the MAPK family, extracellular signalregulated kinase 1/2 (ERK1/2) can be activated in mesangial cells exposed to high glucose (HG) [11]. Also, ERK activity may enhance the TGF- $\beta 1$-dependent responses in human mesangial cells [12]. Therefore, TRB3 may be involved in DN through an ERK pathway.

In this study, we aimed to explore the role of TRB3 in DN and the possible regulating mechanism between TRB3, ERK, and TGF- $\beta 1$ in vivo and in vitro. 


\section{Materials and Methods}

2.1. Main Reagents. We obtained antibodies for TRB3 (Santa Cruz Biotechnology, Santa Cruz, CA), TGF- $\beta 1$ (Abcam Biotechnology, CA), and PD98059, phospho-ERK1/2, and total ERK1/2 (Cell Signaling Technology, Beverly, MA). Trizol reagent and reagents for RT-PCR were from Takara Biotechnology (Dalian, China). ELISA kits for collagen types I and IV were from R\&D systems (Minneapolis, MN).

2.2. Experimental Animals. SPF db/db diabetic mice (C57BL/ $\mathrm{KSJ})$ and their matched (12-week-old) controls $(\mathrm{db} / \mathrm{m})$ were obtained from Vital River Laboratory Animal Technology (Beijing). All animals were maintained on a normal diet under standard animal house conditions at the cardiovascular remodeling Laboratory Animal Center in Qilu Hospital of Shandong University. Animal experiments were conducted in accordance with guidelines established by the Animal Care and Use Committee of Shandong University.

Animals were divided into 3 groups $(n=5)$ and killed at 16, 20, and 25 weeks. Blood glucose and body weight were randomly monitored weekly; levels of urinary albumin excretion, serum creatinine, and blood urea nitrogen (BUN) were detected before death once. The left kidney pieces fixed in $4 \%$ paraformaldehyde were embedded in paraffin, sectioned at $4 \mu \mathrm{m}$ thickness, and mounted on glass slides. The slides were used for morphological observation and immunohistochemical staining to detect the expression of TRB3; the right kidney was snap-frozen in liquid nitrogen and stored at $-80^{\circ} \mathrm{C}$ for RT-PCR and western blot analysis.

2.3. Histology. Sections were stained with hematoxylin and eosin (H\&E), periodic acid Schiff (PAS), and Masson trichrome for investigating renal pathological changes. Paraffin sections were dewaxed and washed in phosphate buffered saline (PBS) and then incubated in preheated $10 \mathrm{mmol} / \mathrm{L}$ sodium citrate buffer at $94^{\circ} \mathrm{C}$ for $15 \mathrm{~min}$. Slides were washed and blocked with protein-blocking solution (10\% normal goat serum) for $30 \mathrm{~min}$ and then incubated with rabbit anti-mouse TRB3 antibody $(1: 100)$ overnight at $4^{\circ} \mathrm{C}$, biotinlabeled secondary antibody working solution for $30 \mathrm{~min}$ at $37^{\circ} \mathrm{C}$, and then DAB color. Sections were preincubated with PBS as negative controls.

2.4. Cell Culture. Mycoplasma-free SV40 MES 13 cells (murine mesangial cells, MMCs) were purchased from China Center for Type Culture Collection. They were derived from glomerular explants of SV40 transgenic mice and showed both biochemical and morphological features of normal mesangial cells in culture. They were maintained in DMEMF12 $(3: 1)$ containing $6 \mathrm{mM}$ glucose and supplemented with $14 \mathrm{mM}$ HEPES and $5 \%$ fetal bovine serum in $5 \% \mathrm{CO}_{2}$ and $95 \%$ humidified air at $37^{\circ} \mathrm{C}$ as described previously $[13,14]$. Cells were synchronized by culturing in serum-free medium for $24 \mathrm{~h}$ before testing and all experiments were performed with cells between passages 30 and 40 to minimize the effects of phenotypic variation in continuous culture.
Mesangial cells were divided by glucose concentration into 3 groups: (1) normal glucose (NG, $5.6 \mathrm{mM}$ glucose, and control); (2) HG (25 mM glucose); and (3) NG + high mannitol (HM, NG plus $19.5 \mathrm{mM}$ mannitol). To investigate the effects of glucose on the expression of TRB3 and pERK1/2, cells were stimulated with HM or HG for $6,12,24$, and $48 \mathrm{~h}$. At the end of each time, total RNA and protein of the cells were extracted for TRB3 and pERK1/2 expression.

To examine the effect of the MAPK pathway on collagen expression by HG, a specific ERK inhibitor (PD98059, $10 \mu \mathrm{mol} / \mathrm{L}$ ) was added $1 \mathrm{~h}$ before stimulation. To examine the effect of TRB3 on collagen expression by HG, TRB3 small interfering RNA (siRNA) was transfected $6 \mathrm{~h}$ before stimulation and cultured for $48 \mathrm{~h}$ in NG or HG medium; then, total RNA and protein were extracted from cells for analysis of TRB3, TGF- $\beta 1$, and pERK1/2 expression and culture medium was collected for measurement of concentration of collagen types I and IV.

2.5. siRNA Transfection. Cells were replated and transfected in 6-well plates with $150 \mu \mathrm{L}$ Opti-MEM (Invitrogen, CA) and $1.5 \mu \mathrm{L} /$ well Lipofectamine 2000 (Invitrogen, CA) with 20 pmol siRNA and its controls. The sense and antisense sequences of the primers were $5^{\prime}$-GCACAGAGUACACCUGCAATT- $3^{\prime}$ and $5^{\prime}$-UUGCAGGUGUACUCUGUGCTT- $3^{\prime}$. As a negative control, we used randomly mixed sequences of TRB3 siRNA, $5^{\prime}$-UUCUCCGAACGUGUCACGUTT- ${ }^{\prime}$, and $5^{\prime}$-ACGUGACACGUUCGGAGAATT- $3^{\prime}$. The effect of siRNA knockdown of TRB3 on the expression of TGF- $\beta 1$ and collagen types I and IV was evaluated by western blot analysis or ELISA at $48 \mathrm{~h}$. All RNAi experiments were repeated at least 3 times.

2.6. Real-Time Quantitative PCR. Total RNA was extracted by use of Trizol. In total, $1 \mu \mathrm{g}$ total RNA was reversetranscribed in a $20 \mathrm{~mL}$ volume containing $0.5 \mathrm{mg}$ oligo-dT primer, $1 \mathrm{~mL}$ dNTP mixture, $1.25 \mathrm{~mL}$ RNase inhibitor, and $4 \mathrm{U}$ reverse transcriptase. Real-time quantitative PCR involved the SYBR-based method in a $20 \mathrm{~mL}$ reaction in a Roche light-cycler. Reaction specificity was confirmed by analyzing melting curves and by electrophoresis on $2.0 \%$ agarose gel analysis of products. The relative change in gene expression was analyzed by the $2^{-\Delta \mathrm{Ct}}$ method and normalized to the expression of the housekeeping gene $\beta$-actin. Respective primer and product specifications are in Table 1.

2.7. Western Blot Analysis. Total protein was extracted from tissues and cells as described previously. The protein extracts were separated on $10 \%$ SDS-PAGE then transferred to PVDF membranes, and blocked in TBST with 5\% skim milk at room temperature for $2 \mathrm{~h}$. The blots were incubated with antibodies for TRB3 (1:200), TGF- $\beta 1$ (1:200), pERK1/2 (1:2000), ERK1/2 $(1: 1000)$, and $\beta$-actin $(1: 1000)$ overnight at $4^{\circ} \mathrm{C}$, washed, and then incubated with goat anti-rabbit antibody $(1: 10000)$ at room temperature for $1 \mathrm{~h}$. Protein bands were analyzed by use of AlphaView SA software. All experiments were repeated at least 3 times. 
TABLE 1: Primers used for RT-PCR.

\begin{tabular}{|c|c|c|c|}
\hline Name & GenBank accession & Primers & Size (bp) \\
\hline \multirow{2}{*}{ TRB3 } & \multirow{2}{*}{ NM 175093.2} & Forward: 5'-GCTCTGAGGCTCCAGGACAA- $3^{\prime}$ & \multirow{2}{*}{91} \\
\hline & & Reverse: 5' -TGTCATCAAACTCCAACGGTTTC-3' & \\
\hline \multirow{2}{*}{ TGF- $\beta 1$} & \multirow{2}{*}{ NM 011577.1} & Forward: $5^{\prime}$-GTGTGGAGCAACATGTGGAACTCTA-3' & \multirow{2}{*}{174} \\
\hline & & Reverse: 5'-CGCTGAATCGAAAGCCCTGTA-3' & \\
\hline \multirow{2}{*}{ Collagen type I $\alpha 1$} & \multirow{2}{*}{ NM 007742.3} & Forward: $5^{\prime}$-CAACAGTCGCTTCACCTACAGC-3' & \multirow{2}{*}{201} \\
\hline & & Reverse: $5^{\prime}$-GTGGAGGGAGTTTACACGAAGC-5' & \\
\hline \multirow{2}{*}{ Collagen Type IV $\alpha 1$} & \multirow{2}{*}{ NM 009931.2} & Forward: $5^{\prime}$-TATGTCCAAGGCAACGAGC-5' & \multirow{2}{*}{228} \\
\hline & & Reverse: 5'-AACCGCACACCTGCTAATG-3' & \\
\hline \multirow{2}{*}{$\beta$-Actin } & \multirow{2}{*}{ NM 007393.3} & Forward: $5^{\prime}$-GTG ACG TTG ACA TCC GTA AAG A-3' & \multirow{2}{*}{245} \\
\hline & & Reverse: $5^{\prime}$-GCC GGA CTC ATC GTA CTC C-3' & \\
\hline
\end{tabular}

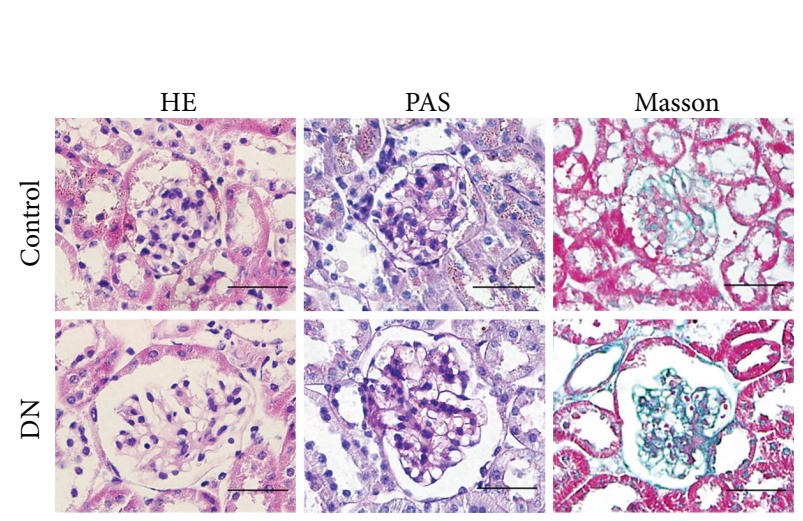

(a)

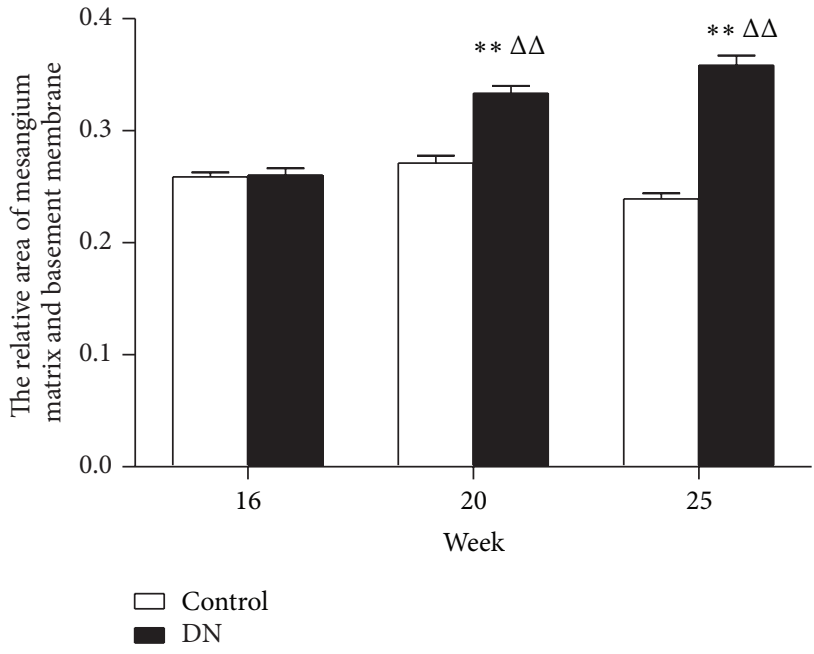

(b)

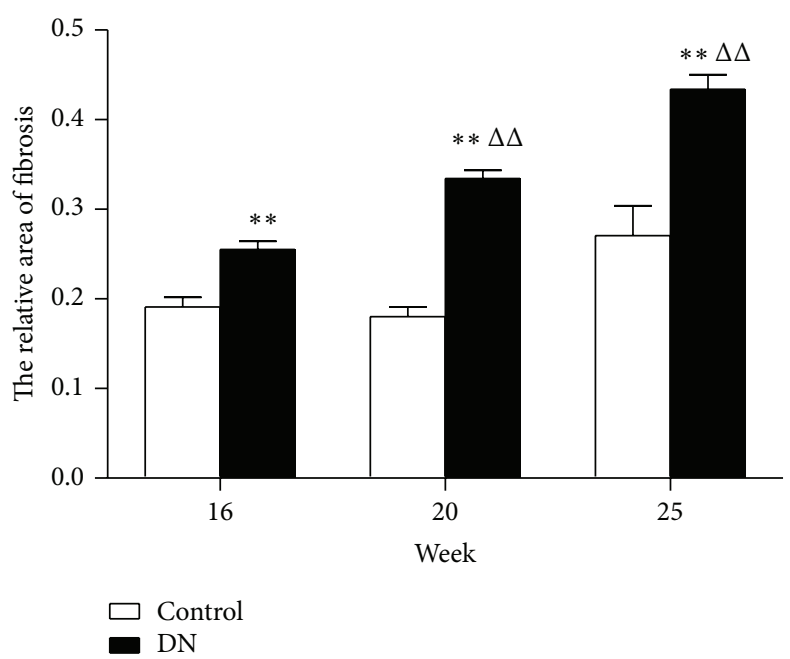

(c)

FIGURE 1: Glomerular pathological changes in mice with diabetic nephropathy (DN) and control mice. (a) Renal morphology and glycogen accumulation at 25 weeks evaluated by hematoxylin and eosin (HE) and periodic acid Schiff (PAS) staining, renal interstitial fibrosis detected by Masson trichrome staining. (b) Relative area of mesangium matrix and basement membrane at different times. (c) Relative area of renal interstitial fibrosis at different times. In both experiments, more than 12 glomeruli were evaluated in each mouse. Magnification in (a) HE, PAS, Masson: 400x. ${ }^{*} P<0.05,{ }^{* *} P<0.01$ versus age-matched control mice. ${ }^{\Delta} P<0.05,{ }^{\Delta \Delta} P<0.01$ versus 16 -week-old DN mice. Scale bars, $50 \mu \mathrm{m} . n=5$ mice per group. 


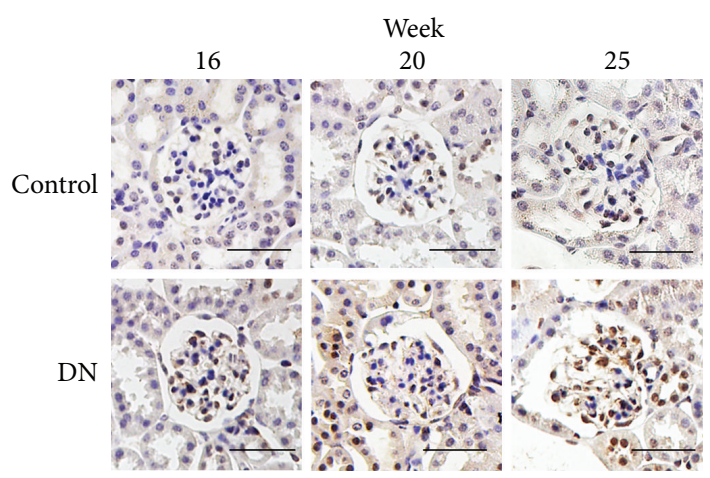

(a)
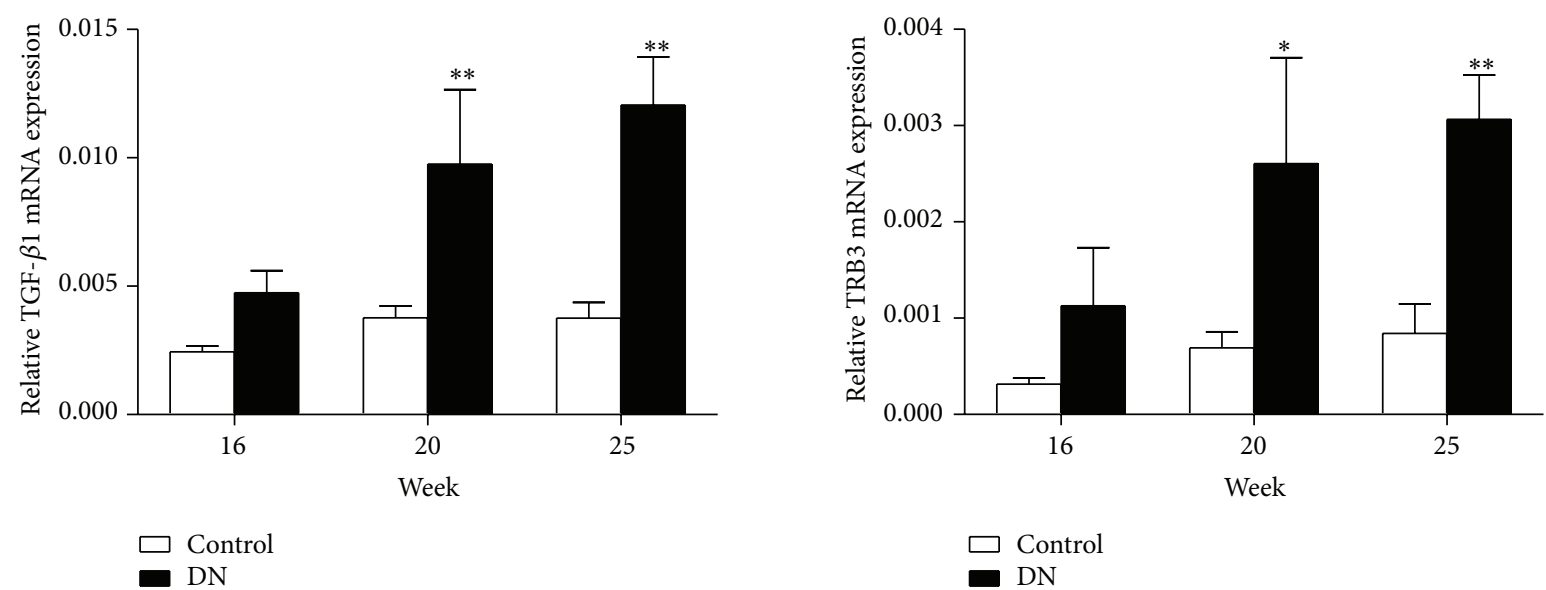

$\square$ Control

- $\mathrm{DN}$

(b)

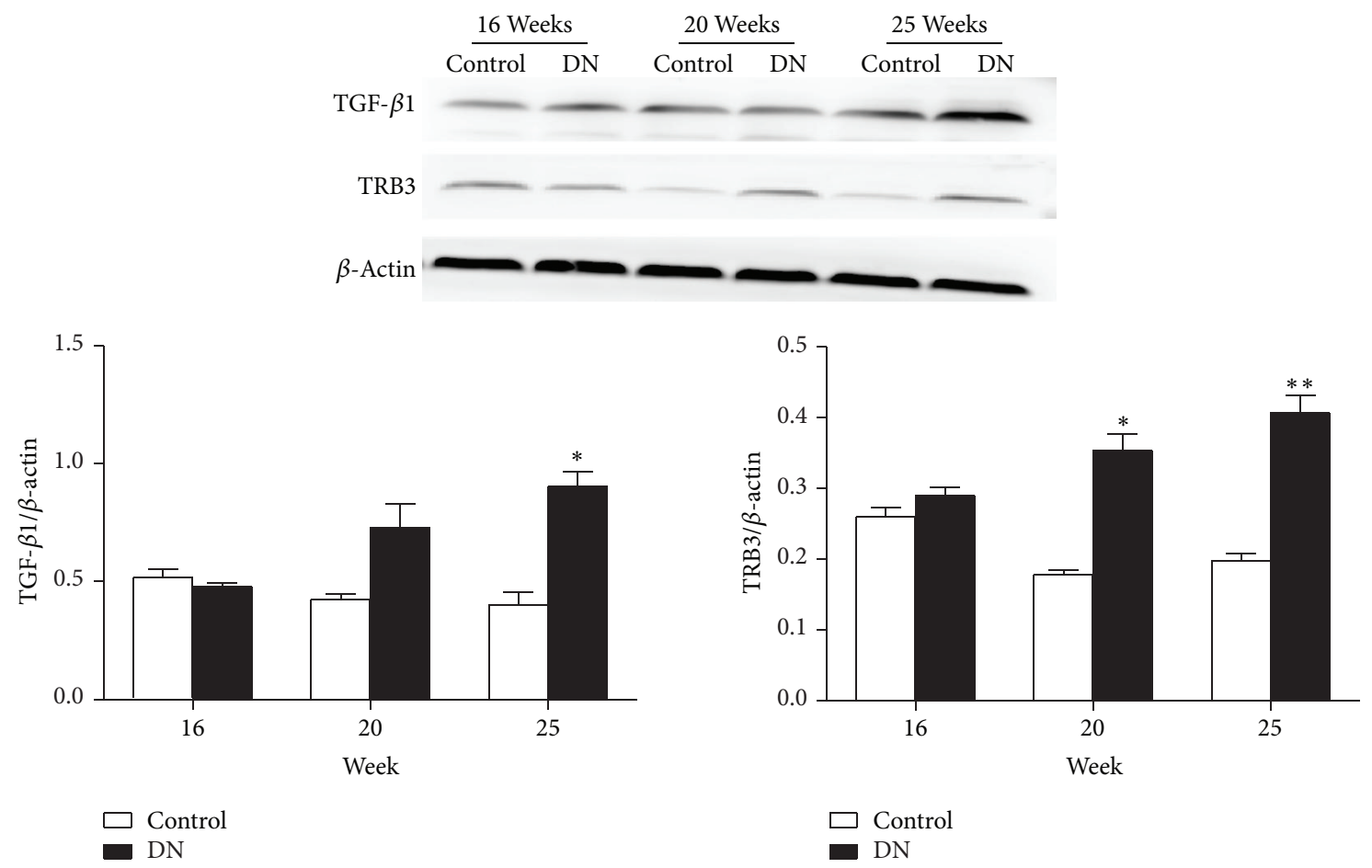

(c)

FIGURE 2: mRNA and protein expression of TGF- $\beta 1$ and TRB3 upregulated in DN mice. (a) Protein TRB3 level in nucleus of intrinsic glomerular cells and tubular epithelial cells. Total TGF- $\beta 1$ and TRB3 mRNA (b) and protein (c) levels by RT-PCR and western blot analysis, respectively. ${ }^{*} P<0.05,{ }^{* *} P<0.01$ versus age-matched control mice. Scale bars, $50 \mu \mathrm{m} . n=5$ mice per group. 


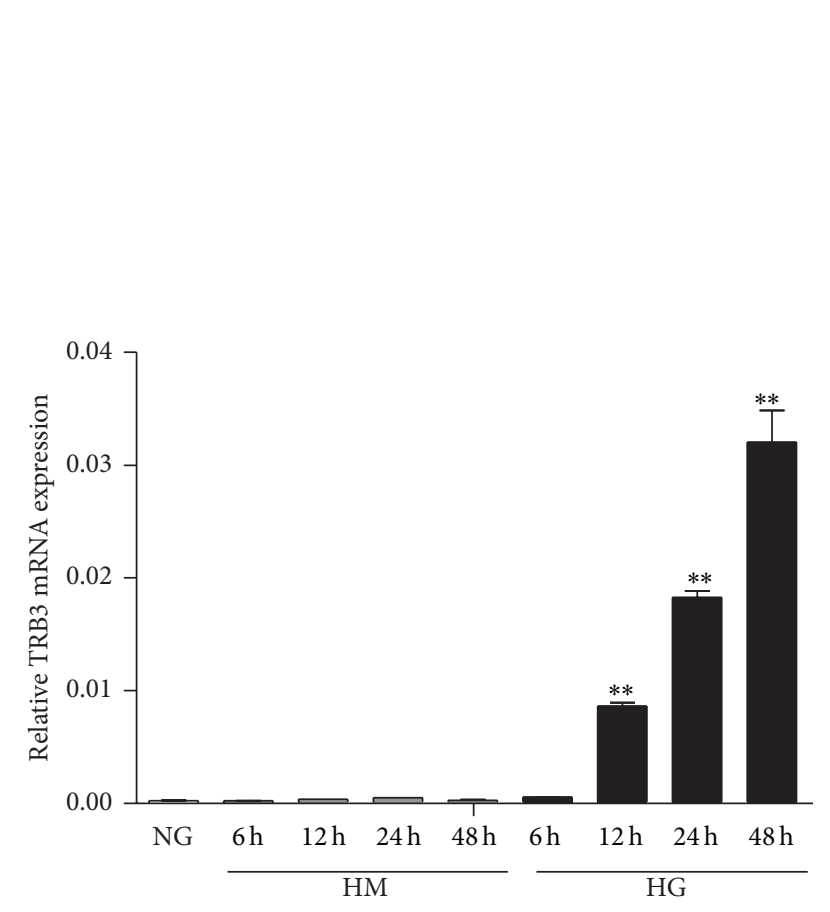

(a)
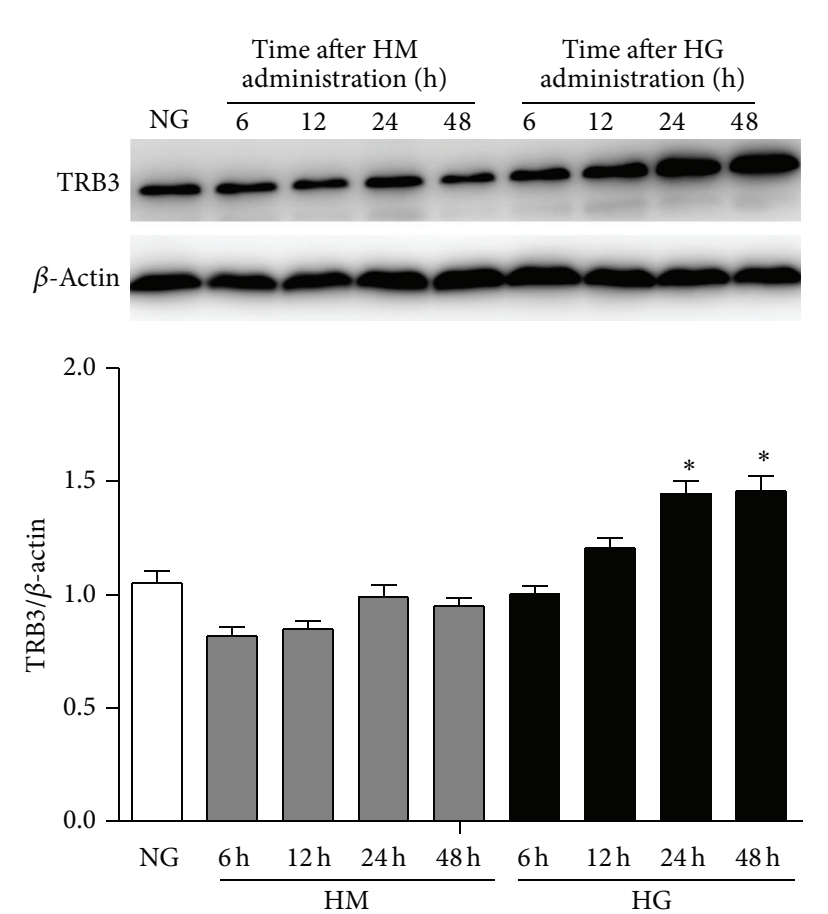

(b)

FIGURE 3: Effect of high glucose (HG) on TRB3 mRNA and protein levels in murine mesangial cells (MMCs) over time. MMCs were cultured in media containing NG and then stimulated with NG + high mannitol (HM) or HG for 6, 12, 24, and 48 h. (a) RT-PCR analysis of the mRNA level of TRB3. (b) Western blot analysis of the protein level of TRB3. Data are mean \pm SEM. ${ }^{*} P<0.05,{ }^{* *} P<0.01$ versus NG.

2.8. ELISA. Soluble collagen types I and IV proteins were determined by ELISA kits according to the manufacturer's protocol. The kits for mouse collagen types I and IV were species-specific and sensitive up to 1000,10 , and $20 \mathrm{ng} / \mathrm{mL}$. All concentrations of proteins were normalized to the total protein amount.

2.9. Statistical Analyses. All values were expressed as means \pm SEM. Images were analyzed by use of Image-Pro Plus 6.0 for semiquantitative analysis. Groups were compared by one-way ANOVA and correlation analysis involved Pearson correlation coefficient. Statistical analysis involved SPSS v17.0 for Windows (SPSS Inc., Chicago, IL). $P<0.05$ was considered statistically significant.

\section{Results}

3.1. Evaluation of the DN Mouse Model. The blood glucose results for control mice remained stable, whereas DN mice showed hyperglycemia. Levels of UAE, Scr, and BUN and body weight were higher for $\mathrm{db} / \mathrm{db}$ mice than age-matched controls $(P<0.05, P<0.01)$ (Table 2$)$. Mesangial matrix expansion and mesangial area were wider for $\mathrm{DN}$ than control mice. At 25 weeks, DN mice showed diffuse and nodular mesangial sclerosis (Figure 1(a)), and the area of mesangium matrix and basement membrane was increased (Figure 1(b)) as was the relative fibrosis area (Figure 1(c)).
3.2. TRB3 Expression Increased in Kidney of DN Mice. TRB3 was expressed mainly in the nucleus of intrinsic glomerular cells and tubular epithelial cells (Figure 2(a)). The expression of TRB3 was higher in DN than control mice. The mRNA and protein expression of TRB 3 and TGF- $\beta 1$ were higher in DN than control mice from 20 weeks and increased with time (Figures 2(b) and 2(c)). The protein level of TRB3 was positively correlated with TGF- $\beta 1$ level $(r=0.944, P<0.01)$ and renal interstitial fibrosis $(r=0.857, P<0.05$ in DN mice).

3.3. Effect of $H G$ on the Expression of TRB3 in MMCs. To confirm the effect of glucose on the expression of TRB3, MMCs were stimulated with HG or HM for various times. The mRNA level of TRB3 was increased within $12 \mathrm{~h}$ after HG stimulation and peaked at $48 \mathrm{~h}(P<0.01$, versus NG; Figure 3(a)). TRB3 protein level was increased under $H G$ at 12, 24, and $48 \mathrm{~h}$ (Figure 3(b)). This increase also peaked at $48 \mathrm{~h}(P<0.05$, versus NG). However, levels did not increase significantly under HM at different times. Thus, HG can upregulate the expression of TRB3 in MMCs.

3.4. HG Upregulated the Expression of TGF- $\beta 1$ and Collagen Type IV in Cultured Cells. As compared with NG, HG time-dependently increased both the mRNA and protein expression of TGF- $\beta 1$ and collagen type IV (Figure 4 ) within $48 \mathrm{~h}$ and $12 \mathrm{~h}$, respectively, for mRNA and for both within $48 \mathrm{~h}$ for protein $(P<0.01$, versus NG). However, collagen 


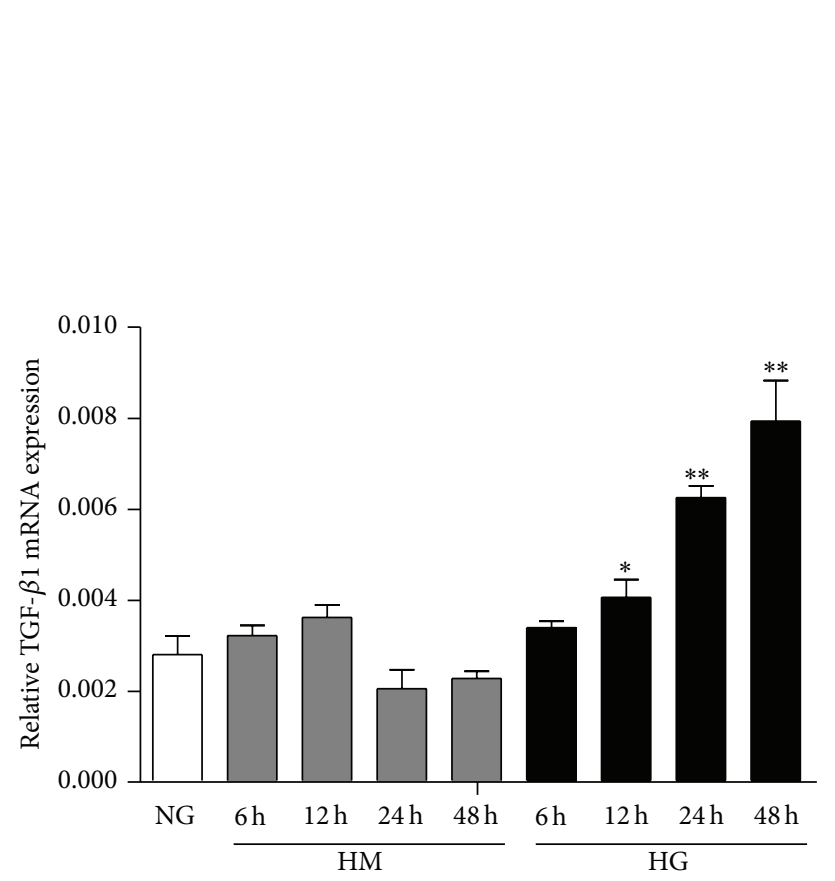

(a)

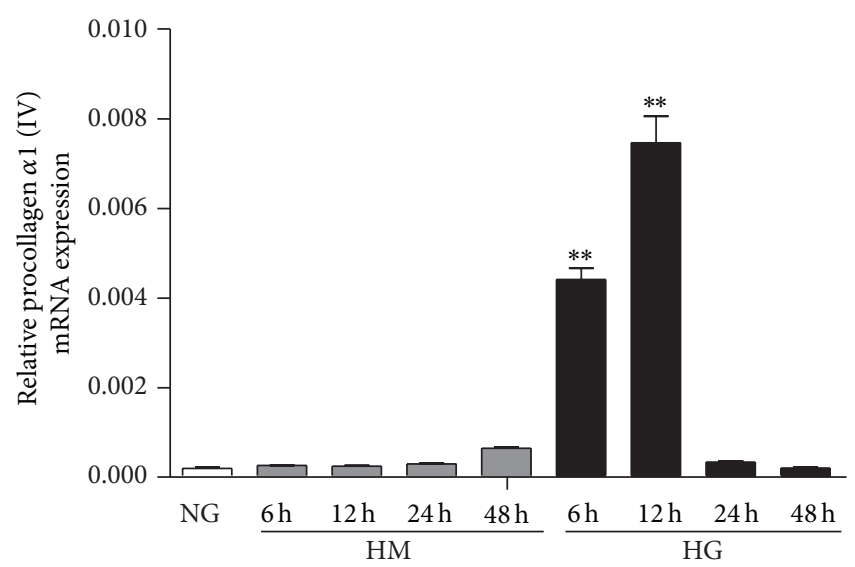

(c)
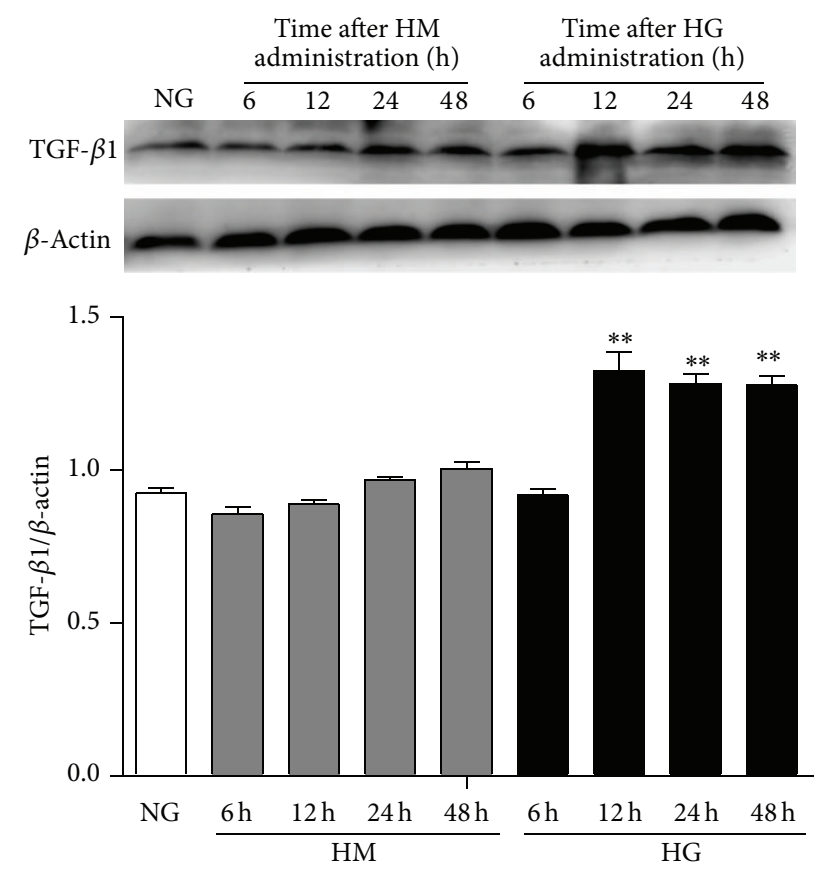

(b)

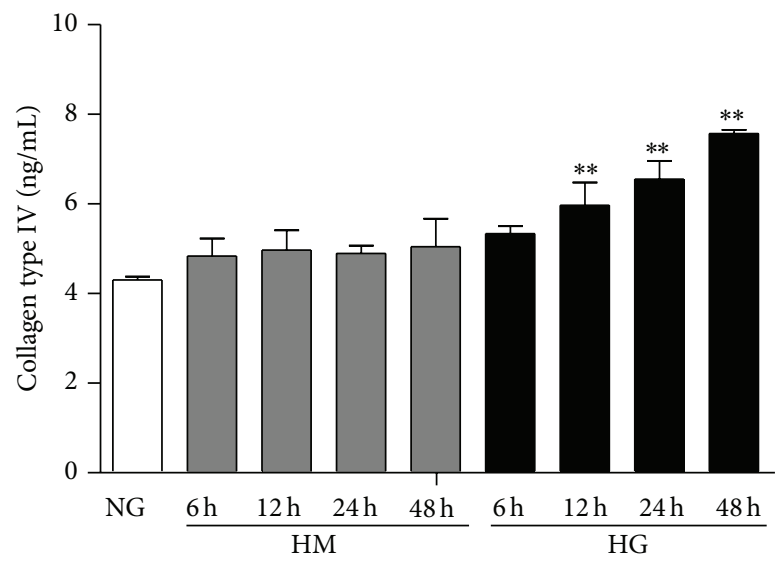

(d)

FIGURE 4: Effect of HG on mRNA and protein levels of TGF- $\beta 1$ and collagen type IV in MMCs over time. MMCs were cultured in media containing NG and then stimulated with HM or HG for $6,12,24$, and $48 \mathrm{~h}$. (a) and (c) RT-PCR analysis of mRNA levels of TGF- $\beta 1$ and collagen type IV, respectively. (b) Western blot analysis of protein level of TGF- $\beta 1$. (d) ELISA of secretion of collagen type IV. Data are mean \pm SEM. ${ }^{*} P<0.05,{ }^{* *} P<0.01$ versus NG.

TABLE 2: Metabolic data of mice in different groups by time.

\begin{tabular}{lcccccc}
\hline & \multicolumn{2}{c}{ 16 weeks } & \multicolumn{2}{c}{20 weeks } & \multicolumn{2}{c}{25 weeks } \\
& $\mathrm{C}$ & $\mathrm{DN}$ & $\mathrm{C}$ & $\mathrm{DN}$ & $\mathrm{C}$ & $\mathrm{DN}$ \\
\hline $\mathrm{BW}(\mathrm{mg})$ & $22.80 \pm 2.52$ & $47.86 \pm 0.83^{* *}$ & $22.54 \pm 1.24$ & $52.26 \pm 2.47^{* *}$ & $23.26 \pm 0.67$ & $47.52 \pm 2.56^{* *}$ \\
$\mathrm{RBG}(\mathrm{mmol} / \mathrm{L})$ & $4.48 \pm 0.71$ & $12.33 \pm 1.67^{* *}$ & $4.78 \pm 0.84$ & $24.15 \pm 1.62^{* * \Delta}$ & $5.92 \pm 0.87$ & $33.08 \pm 1.54^{* * \Delta}$ \\
$\mathrm{UAE}(\mu \mathrm{g} / 24 \mathrm{~h})$ & $27.68 \pm 1.65$ & $386.12 \pm 16.30^{* *}$ & $24.20 \pm 1.45$ & $452.12 \pm 32.26^{* * \Delta}$ & $27.24 \pm 1.52$ & $551.78 \pm 29.19^{* * \Delta \Delta}$ \\
BUN $(\mathrm{mmol} / \mathrm{L})$ & $8.32 \pm 0.37$ & $9.38 \pm 0.29^{*}$ & $8.56 \pm 0.43$ & $9.94 \pm 0.20^{* *}$ & $8.44 \pm 0.45$ & $10.48 \pm 0.18^{* * \Delta}$ \\
Scr $(\mathrm{mmol} / \mathrm{L})$ & $14.80 \pm 0.58$ & $28.2 \pm 1.7$ & $18.00 \pm 1.30$ & $33.60 \pm 3.37^{* *}$ & $16.60 \pm 1.67$ & $25.40 \pm 2.77^{* *}$ \\
\hline
\end{tabular}

Data are means \pm SEM. C: control; DN: diabetic nephropathy; BW: body weight; UAE: urinary albumin excretion; BUN: blood urea nitrogen; Scr: serum creatinine.

${ }^{*} P<0.05,{ }^{* *} P<0.01$ versus age-matched control mice.

${ }^{\triangle} P<0.05,{ }^{\triangle} \triangle P<0.01$ versus 16 -week-old $\mathrm{db} / \mathrm{db}$ mice. 

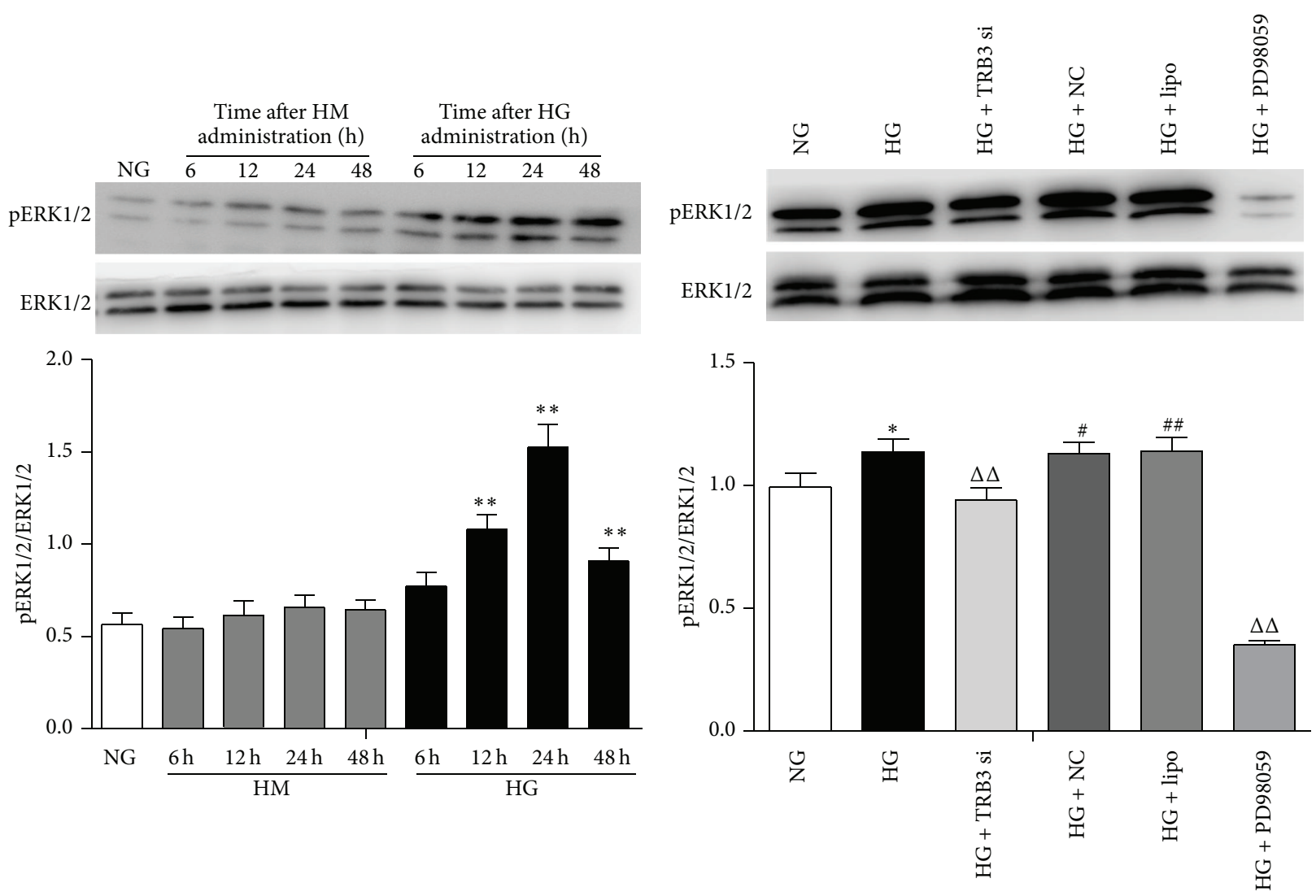

(a)

(b)

FIGURE 5: Effect of TRB3 on phosphorylated ERK1/2 (pERK1/2) expression in cells. (a) Western blot analysis of pERK1/2 level in cells incubated with HM or HG for 6, 12, 24, and $48 \mathrm{~h}$. (b) Cells were transfected with TRB3 siRNA or corresponding negative control. Western blot analysis of pERK1/2 level with HG stimulation for $48 \mathrm{~h}$. Data are mean \pm SEM. ${ }^{*} P<0.05,{ }^{* *} P<0.01$ versus NG, ${ }^{\Delta \triangle} P<0.01$ versus HG, and ${ }^{\#} P<0.05$, ${ }^{\#} P<0.01$ versus NG + TRB3 siRNA.

type I expression did not change under any conditions within $48 \mathrm{~h}$ (data not shown). Therefore, HG increased TGF- $\beta 1$ and collagen type IV secreted from cultured MMC cells.

\subsection{Effect of TRB3 on Activation of the ERK1/2 MAPK Pathway} in MMCs. To verify the effect of glucose on the activation of the ERK1/2 MAPK pathway in MMCs, cells were cultured in NG medium and then stimulated with HG or HM for various times. The level of $\mathrm{pERK} 1 / 2$ increased during the first $6 \mathrm{~h}(P<0.01$, versus $\mathrm{NG})$ after $\mathrm{HG}$ stimulation and peaked at $24 \mathrm{~h}(P<0.01$, versus NG) (Figure 5(a)). However, stimulation with HM had no effect on the activation of this pathway. Therefore, HG can activate the ERK1/2 pathway in MMCs. To confirm the effect of TRB3 on this pathway, we transfected TRB3 siRNA into MMCs exposed to $\mathrm{HG}$ medium for $24 \mathrm{~h}$ and evaluated pERK1/2 levels. Transient transfection of siRNA into MMCs induced FAM expression, which indicated successful transfection. Expression of FAM increased at $6 \mathrm{~h}$ and peaked at $48 \mathrm{~h}$ (Figure 6(a)). To test the efficacy of the selected siRNA sequence, we measured the protein level of TRB3 after $48 \mathrm{~h}$ transfection with TRB3 siRNA. TRB3 protein expression was lower in MMCs with TRB3 siRNA than in cells with control siRNA $(P<0.05$, versus NG + NC) (Figure 6(b)). pERK1/2 expression was decreased in MMCs transfected with TRB3 siRNA $(P<0.05$, versus HG + NC; Figure 5(b)). TRB3 may activate the ERK1/2 MAPK pathway in MMCs.

3.6. TRB3 is Involved in the Expression of TGF- $\beta 1$ and Collagen Type IV Regulated by High Glucose in DN by Activating ERK1/2 MAPK. The expression of pERK1/2 was markedly reduced by blocking ERK1/2 MAPK signaling by a specific ERK inhibitor (PD98059, $10 \mu \mathrm{mol} / \mathrm{L}$ ) (Figure 5(b)). The mRNA and protein levels of TGF- $\beta 1$ and collagen type IV were decreased with the ERK1/2 pathway blocked (Figures $7(\mathrm{a})-7(\mathrm{~d}), P<0.01$ versus $H G)$ as was the pERK1/2 level (Figure 5(b), $P<0.01$ versus $H G$ ), which suggests that HG can regulate TGF- $\beta 1$ and collagen type IV through the ERK1/2 MAPK pathway. The protein expression of TRB3 was markedly increased after blocking the ERK1/2 MAPK pathway (Figure $7(\mathrm{e}), P<0.01$ versus $H G$ ). This finding indicates a possible feedback regulation between TRB3 and some downstream cytokines of ERK1/2 MAPK.

\section{Discussion}

Here, we found augmented expression of TRB3 in kidneys of $\mathrm{DN}$ mice, which was positively related to TGF- $\beta 1$ expression 

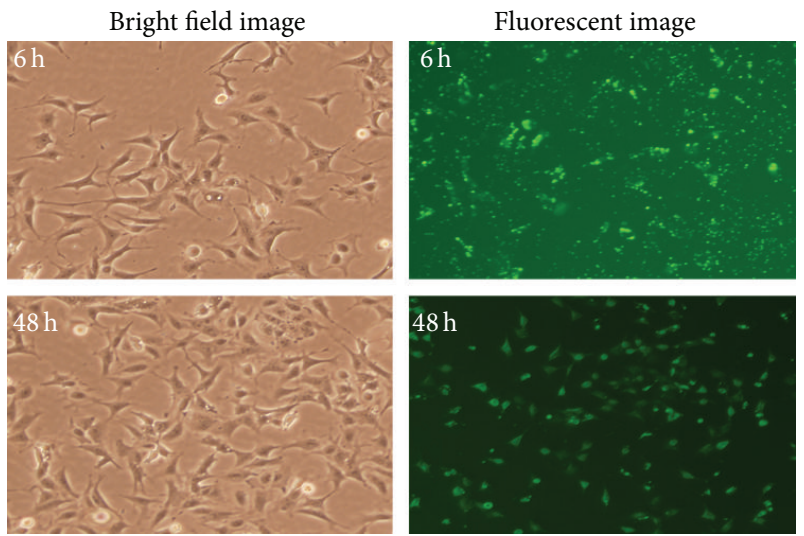

(a)

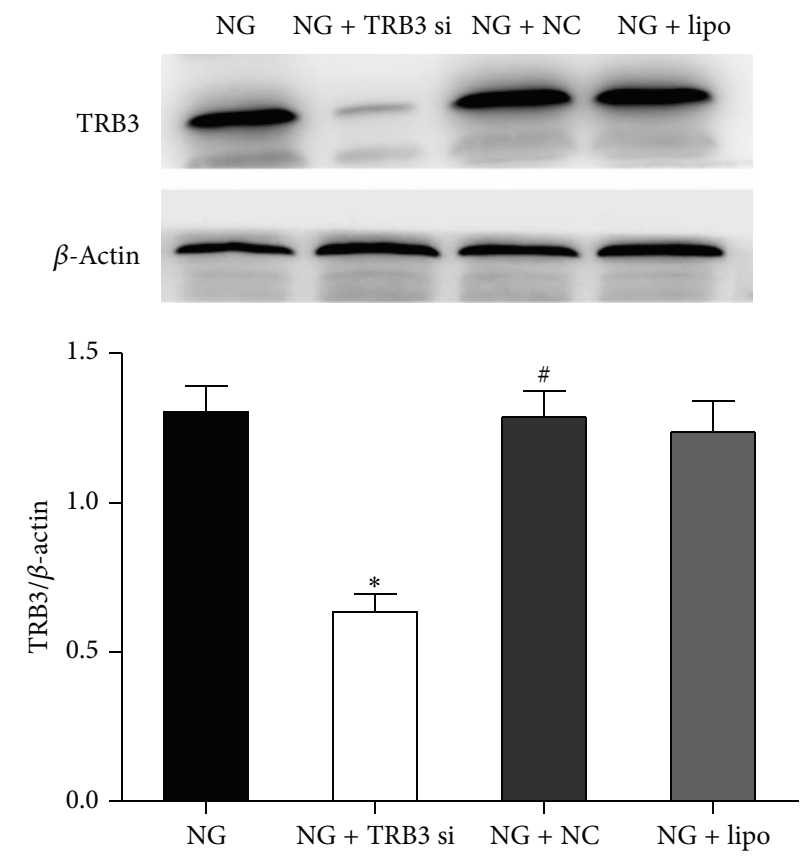

(b)

FIGURE 6: Effect of siRNA on the expression of FAM and TRB3 in cells. Transient transfection of cells with TRB3 siRNA induced FAM expression, indicating successful transfection. FAM expression was observed at 0 and $48 \mathrm{~h}$ after transfection. Cells were transfected with TRB3 siRNA or its corresponding negative control and then incubated with NG (5.5 mM glucose) for $48 \mathrm{~h}$. (a) FAM expression was observed by bright field and fluorescent imaging (200x). (b) Western blot analysis of the protein expression of TRB3 at $48 \mathrm{~h}$ after TRB3 siRNA transfection. Data are mean \pm SEM. ${ }^{*} P<0.05$ versus $N G ;{ }^{\#} P<0.05$ versus NG + TRB3 siRNA.

and renal interstitial fibrosis. HG upregulated the expression of TRB3, TGF- $\beta 1$, collagen type IV, and phosphorylatedERK1/2 MAPK in MMCs. After inhibiting TRB3 with TRB3 siRNA, the HG-induced level of pERK1/2 MAPK was attenuated and HG-induced expression of TGF- $\beta 1$ and collagen type IV decreased. Moreover, the protein expression of TRB3 was increased after blocking the ERK1/2 MAPK pathway. TRB3 may be involved in DN by regulating the fibrosis cytokine TGF- $\beta 1$ and collagen type IV via ERK1/2 MAPK signaling.

Tribbles was first discovered to regulate Drosophila embryogenesis, and it has the same location as the type 2 diabetes gene, so TRB3 may have a natural link with diabetes. Compared with wild-type mice, $\mathrm{db} / \mathrm{db}$ diabetic mice were found to have increased TRB3 mRNA and protein expression in liver; TRB3 expression increased in the $\mathrm{db} / \mathrm{db}$ mouse liver promoted blood glucose and increased glucose tolerance [9]. However, few studies have reported the expression and role of TRBs in DN. We examined the expression of TRB1, TRB2, and TRB3 in the DN mouse kidney and found only TRB3 expressed differently between DN and control groups, so TRB3 could be a potential cytokine to widen the current knowledge of DN. Our further study revealed that the mRNA and protein levels of TRB3 were higher in the DN than normal kidney, which was also positively correlated with TGF- $\beta 1$ protein level and content of collagen. Previous study showed that TRB3 was positively correlated with kidney tissue fibrosis, which may play a role in promoting the progression of fibrosis by inducing the transformation between epithelial and mesenchymal tissue [15]. Therefore, TRB3 may be involved in $\mathrm{DN}$ by inducing interstitial fibrosis, in which TGF- $\beta 1$ plays a key role.

We wondered about the role of TRB3 in the fibrosis of DN and the relationship between TRB3 and TGF- $\beta 1$. Several studies supported that TRB3 may function as a scaffold protein to control MAPK activity [10, 16, 17]. Among the several MAPK signal pathways, the ERK1/2 pathway is activated under $\mathrm{HG}$ in mesangial cells, followed by the complicated synthesis of TGF- $\beta 1$ [18]. The activation of the ERK1/2 pathway is necessary for HG-induced production of TGF- $\beta 1$ and connective tissue growth factor (CTGF) in MMCs [19]. Our preliminary study excluded the involvement of the p-38 and JNK MAPK pathway. Therefore, we focused on the ERK MAPK pathway. Silencing TRB3 decreased ERK1/2 activation, followed by decreased $\mathrm{mRNA}$ and protein levels of TGF- $\beta 1$ and collagen type IV in MMCs, so TRB3 may participate in renal fibrosis of DN by upregulating TGF- $\beta 1$ and collagen type IV in MMCs via ERK MAPK signaling. To our knowledge, our study is the first to reveal the interaction between TRB3, ERK1/2, and TGF- $\beta 1$ in renal tissue of DN.

Recently, TRB3 was found stimulated in diabetic kidneys, regulated by the ER stress marker $\mathrm{CHOP}$, and inhibited the podocyte expression of monocyte chemoattractant protein 1, which first suggested that TRB3 plays a protective role in diabetic kidney disease [20]. These findings that differ from our results may be due to cell specificity [21]; we used mesangial cells, but the previous study used podocytes. 


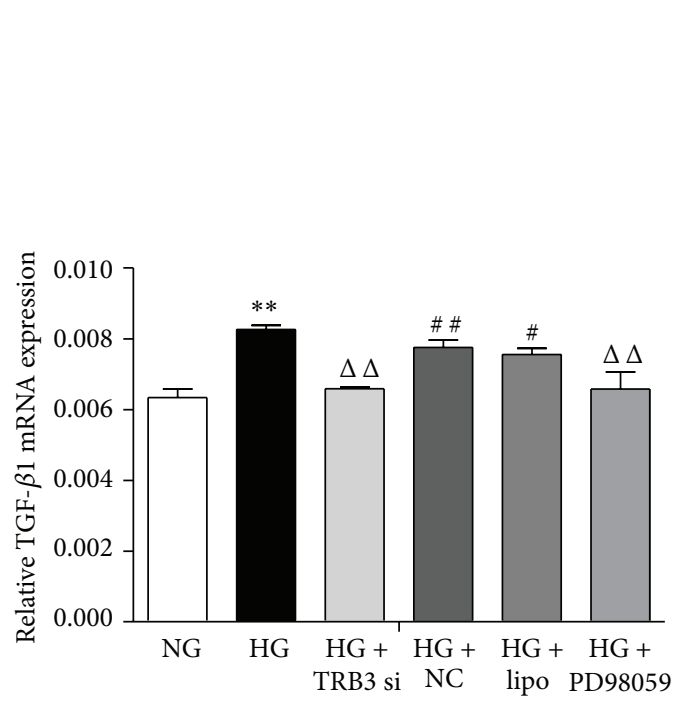

(a)

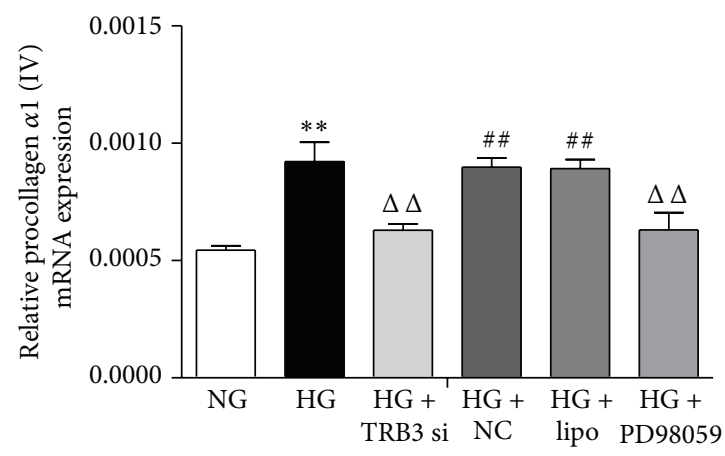

(c)
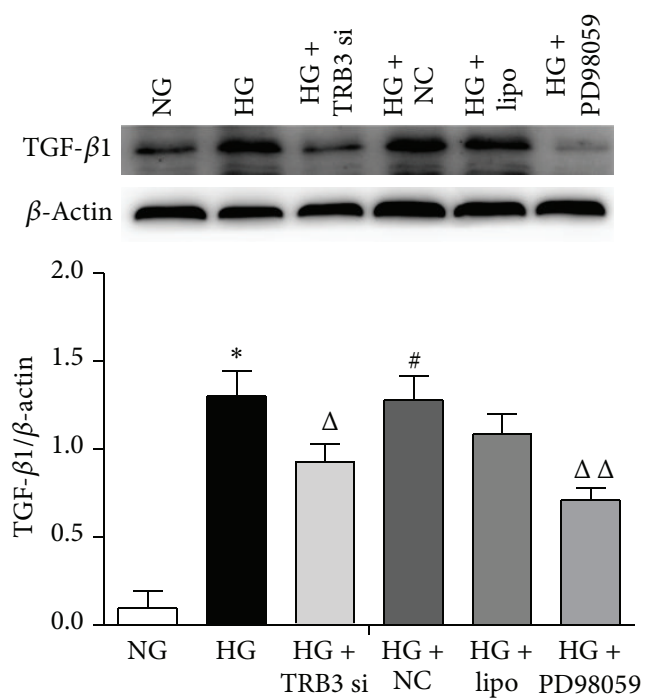

(b)

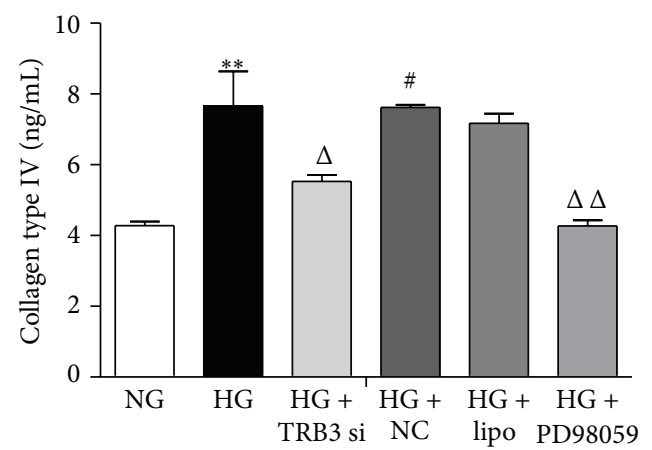

(d)
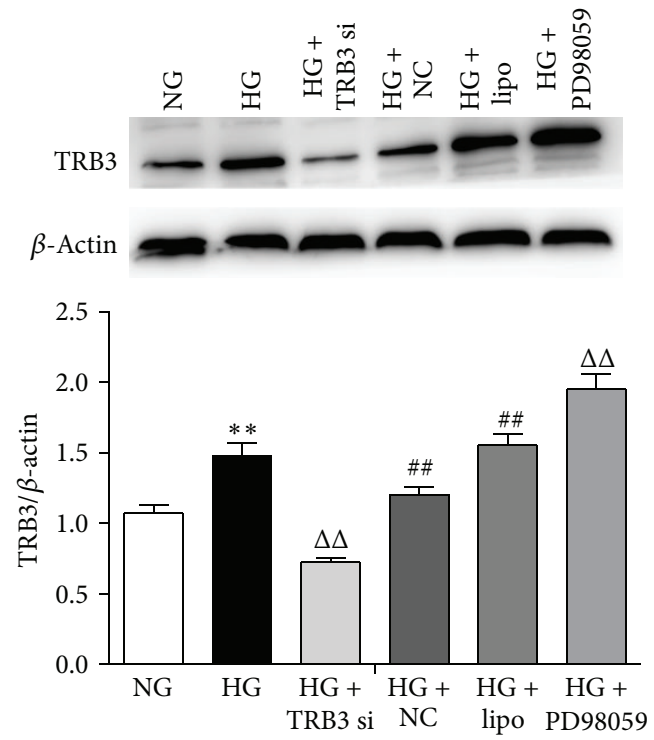

(e)

FIGURE 7: Effect of silencing TRB3 protein or blocking ERK1/2 MAPK pathway by a specific ERK inhibitor (PD98059, $10 \mu \mathrm{mol} / \mathrm{L})$ on HG induction of TGF- $\beta 1$, collagen type IV, and TRB3 level in MMCs. (a) and (b) mRNA level of TGF- $\beta 1$ at $12 \mathrm{~h}$ and protein level at $48 \mathrm{~h}$; (c) and (d) mRNA level of collagen type IV at $12 \mathrm{~h}$ and protein level at $48 \mathrm{~h}$. MMCs were stimulated with NG or HG after blockade of TRB3 with TRB3 siRNA. (e) Protein expression of TRB3 at $48 \mathrm{~h}$. Data are mean \pm SEM. ${ }^{*} P<0.05$, ${ }^{* *} P<0.01$ versus NG; ${ }^{\Delta} P<0.05,{ }^{\Delta \Delta} P<0.01$ versus HG; ${ }^{\#} P<0.05,{ }^{\# \#} P<0.01$ versus NG + TRB3 siRNA. 
Moreover, signal transduction in vivo is a complex system. Numerous cytokines may interact through different pathways, and different signal pathways may have "crosstalk." So, the role of TRB3 in DN can also be studied from other signal pathways. TRB3 plays a role in the pathogenesis of DN by participating in insulin resistance, functioning as a negative modulator of Akt $[9,22,23]$. Another study showed that TRB3 may cause renal cell apoptosis by participating in the $\mathrm{NF}-\kappa \mathrm{B}$ pathway and thus participate in the process of renal fibrosis in DN $[24,25]$. Even Smad3 is considered to mediate TRB3 enhancing TGF- $\beta$ signaling [26]. There must be some interactions between ERK, Akt, NF- $\kappa$ B, Smad3, and other unknown pathways. More detailed and systemic studies are needed to establish the complete theory on TRB3 involved in DN.

In this study, we found that the expression of TRB3 increased after blocking the ERK1/2 MAPK pathway, which may indicate a negative feedback regulation between TRB3 and some downstream cytokines of ERK1/2 MAPK or special "crosstalk" with other signal pathways, which requires further exploration.

\section{Conclusions}

TRB3 expression is upregulated in renal tissue of DN mice in vivo and MMCs in vitro. TRB3 may be involved in DN by regulating the fibrosis cytokine TGF- $\beta 1$ and collagen type IV via ERK1/2 MAPK signaling.

\section{Conflict of Interests}

The authors declare that there is no conflict of interests regarding the publication of this paper.

\section{Authors' Contribution}

Jinhang Zhang and Luwei Zhang contributed equally to this work.

\section{Acknowledgments}

The authors thank Junhui Zhen and Jing Fu for their assistance. This study was supported by a Grant from the National Natural Science Foundation of China (no. 81000303) and the National Natural Science Foundation of Shandong Province (no. ZR2009CQ036).

\section{References}

[1] P. Ruggenenti and G. Remuzzi, "Nephropathy of type-2 diabetes mellitus," Journal of the American Society of Nephrology, vol. 9, no. 11, pp. 2157-2169, 1998.

[2] H. B. Lee, M. Yu, Y. Yang, Z. Jiang, and H. Ha, "Reactive oxygen species-regulated signaling pathways in diabetic nephropathy," Journal of the American Society of Nephrology, vol. 14, supplement 3, pp. S241-S245, 2003.

[3] E. J. Valk, J. A. Bruijn, and I. M. Bajema, "Diabetic nephropathy in humans: pathologic diversity," Current Opinion in Nephrology and Hypertension, vol. 20, no. 3, pp. 285-289, 2011.
[4] F. C. Brosius III, C. C. Khoury, C. L. Buller, and S. Chen, "Abnormalities in signaling pathways in diabetic nephropathy," Expert Review of Endocrinology and Metabolism, vol. 5, no. 1, pp. 51-64, 2010.

[5] M. W. Steffes, R. W. Bilous, D. E. R. Sutherland, and S. M. Mauer, "Cell and matrix components of the glomerular mesangium in type I diabetes," Diabetes, vol. 41, no. 6, pp. 679-684, 1992.

[6] The Chronic Complications Investigation Group of the Diabetes Society of Chinese Medical Association, "The retrospective analysis about diabetes chronic complications and related macroangiopathy of $\mathrm{n}$ ationwide i npatient s from 1991 to 2000 in China," Journal of Chinese Academy of Medical Sciences University, vol. 5, pp. 447-451, 2002.

[7] M. S. Razzaque, V. T. Le, and T. Taguchi, "Heat shock protein 47 and renal fibrogenesis," Contributions to Nephrology, vol. 148, pp. 57-69, 2005.

[8] M. S. Razzaque and T. Taguchi, "Cellular and molecular events leading to renal tubulointerstitial fibrosis," Medical Electron Microscopy, vol. 35, no. 2, pp. 68-80, 2002.

[9] K. Du, S. Herzig, R. N. Kulkarni, and M. Montminy, “TRB3: a tribbles homolog that inhibits Akt/PKB activation by insulin in liver," Science, vol. 300, no. 5625, pp. 1574-1577, 2003.

[10] E. Kiss-Toth, S. M. Bagstaff, H. Y. Sung et al., "Human tribbles, a protein family controlling mitogen-activated protein kinase cascades," Journal of Biological Chemistry, vol. 279, no. 41, pp. 42703-42708, 2004.

[11] M. Haneda, S. Araki, M. Togawa, T. Sugimoto, M. Isono, and R. Kikkawa, "Mitogen-activated protein kinase cascade is activated in glomeruli of diabetic rats and glomerular mesangial cells cultured under high glucose conditions," Diabetes, vol. 46, no. 5, pp. 847-853, 1997.

[12] T. Hayashida, M. Decaestecker, and H. W. Schnaper, "Crosstalk between ERK MAP kinase and Smad signaling pathways enhances TGF-beta-dependent responses in human mesangial cells," The FASEB Journal, vol. 17, no. 11, pp. 1576-1578, 2003.

[13] R. B. Robey, J. Ma, and A. V. P. Santos, "Regulation of mesangial cell hexokinase activity by PKC and the classic MAPK pathway," American Journal of Physiology: Renal Physiology, vol. 277, no. 5, pp. F742-F749, 1999.

[14] R. B. Robey, B. J. Raval, J. Ma, and A. V. P. Santos, "Thrombin is a novel regulator of hexokinase activity in mesangial cells," Kidney International, vol. 57, no. 6, pp. 2308-2318, 2000.

[15] J. Liu, B. Xin, R. Mu, and F. Hua, "Expression of TRB3 in renal fibrosis and its relation with epithelial-mesenchymal transition," Chinese Pharmacological Bulletin, vol. 28, no. 3, pp. 407-411, 2012.

[16] M. Tang, M. Zhong, Y. Shang et al., "Differential regulation of collagen types I and III expression in cardiac fibroblasts by AGEs through TRB3/MAPK signaling pathway," Cellular and Molecular Life Sciences, vol. 65, no. 18, pp. 2924-2932, 2008.

[17] R. K. Humphrey, C. J. Newcomb, S. A. Yu et al., "Mixed lineage kinase- 3 stabilizes and functionally cooperates with TRIBBLES3 to compromise mitochondrial integrity in cytokine-induced death of pancreatic beta cells," The Journal of Biological Chemistry, vol. 285, no. 29, pp. 22426-22436, 2010.

[18] D. Fraser, N. Brunskill, T. Ito, and A. O. Phillips, "Long-term exposure of proximal tubular epithelial cells to glucose induces transforming growth factor- $\beta 1$ synthesis via an autocrine PDGF loop," The American Journal of Pathology, vol. 163, no. 6, pp. 2565-2574, 2003.

[19] L. Wang, G. Hu, H. Shen, Z. Peng, W. Ning, and L. Tao, "Fluorofenidone inhibits TGF- $\beta 1$ induced CTGF via MAPK 
pathways in mouse mesangial cells," Pharmazie, vol. 64, no. 10, pp. 680-684, 2009.

[20] E. Morse, J. Schroth, N. You et al., "TRB3 is stimulated in diabetic kidneys, regulated by the ER stress marker $\mathrm{CHOP}$, and is a suppressor of podocyte MCP-1," The American Journal of Physiology-Renal Physiology, vol. 299, no. 5, pp. F965-F972, 2010.

[21] H. Y. Sung, S. E. Francis, D. C. Crossman, and E. Kiss-Toth, "Regulation of expression and signalling modulator function of mammalian tribbles is cell-type specific," Immunology Letters, vol. 104, no. 1-2, pp. 171-177, 2006.

[22] L. He, F. A. Simmen, H. M. Mehendale, M. J. J. Ronis, and T. M. Badger, "Chronic ethanol intake impairs insulin signaling in rats by disrupting Akt association with the cell membranerole of TRB3 in inhibition of Akt/protein kinase B activation," Journal of Biological Chemistry, vol. 281, no. 16, pp. 11126-11134, 2006.

[23] R. Schwarzer, S. Dames, D. Tondera, A. Klippel, and J. Kaufmann, "TRB3 is a PI 3-kinase dependent indicator for nutrient starvation," Cellular Signalling, vol. 18, no. 6, pp. 899-909, 2006.

[24] T. Rzymski, A. Paantjens, J. Bod, and A. L. Harris, "Multiple pathways are involved in the anoxia response of SKIP3 including HuR-regulated RNA stability, NF- $\kappa$ B and ATF4," Oncogene, vol. 27, no. 33, pp. 4532-4543, 2008.

[25] N. Lampiasi, A. Azzolina, K. Umezawa, G. Montalto, J. A. McCubrey, and M. Cervello, "The novel NF- $\kappa$ B inhibitor DHMEQ synergizes with celecoxib to exert antitumor effects on human liver cancer cells by a ROS-dependent mechanism," Cancer Letters, vol. 322, no. 1, pp. 35-44, 2012.

[26] F. Hua, R. Mu, J. Liu et al., "TRB3 interacts with SMAD3 promoting tumor cell migration and invasion," Journal of Cell Science, vol. 124, no. 19, pp. 3235-3246, 2011. 


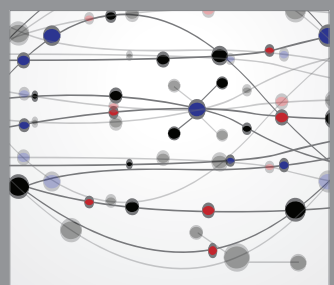

The Scientific World Journal
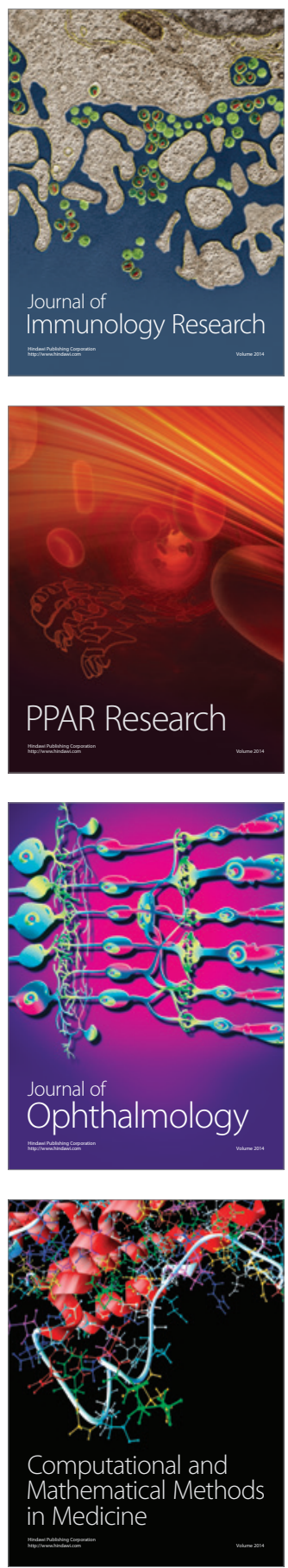

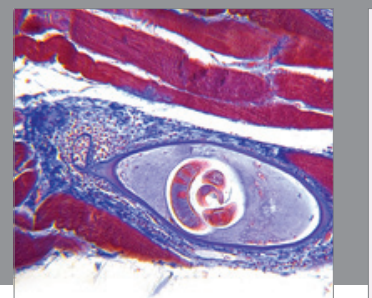

Gastroenterology

Research and Practice
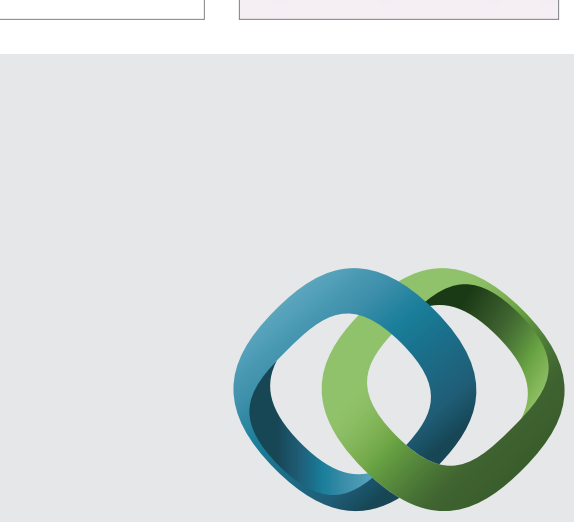

\section{Hindawi}

Submit your manuscripts at

http://www.hindawi.com
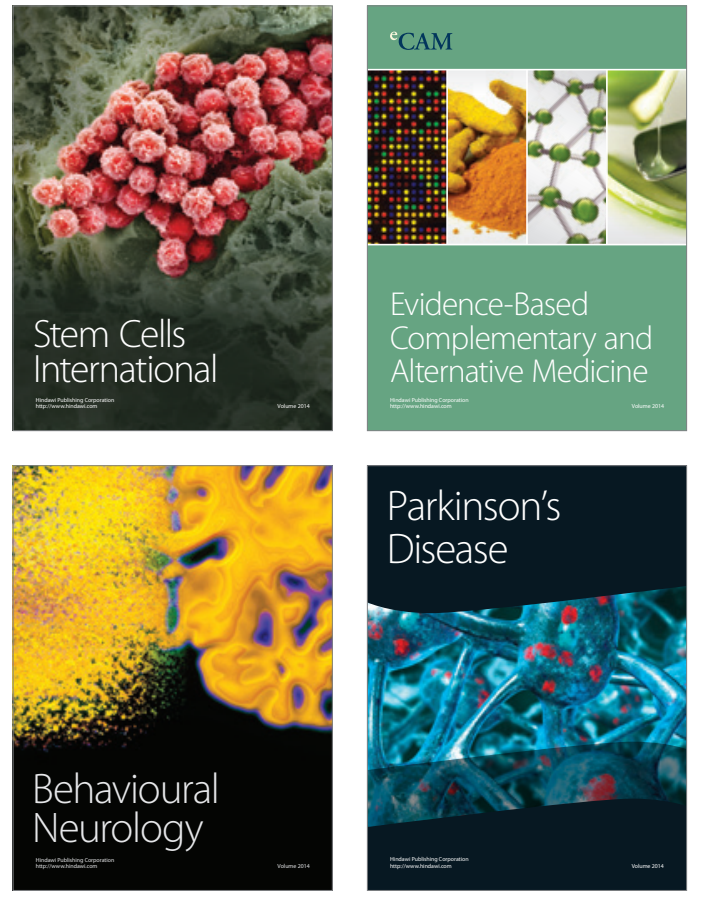
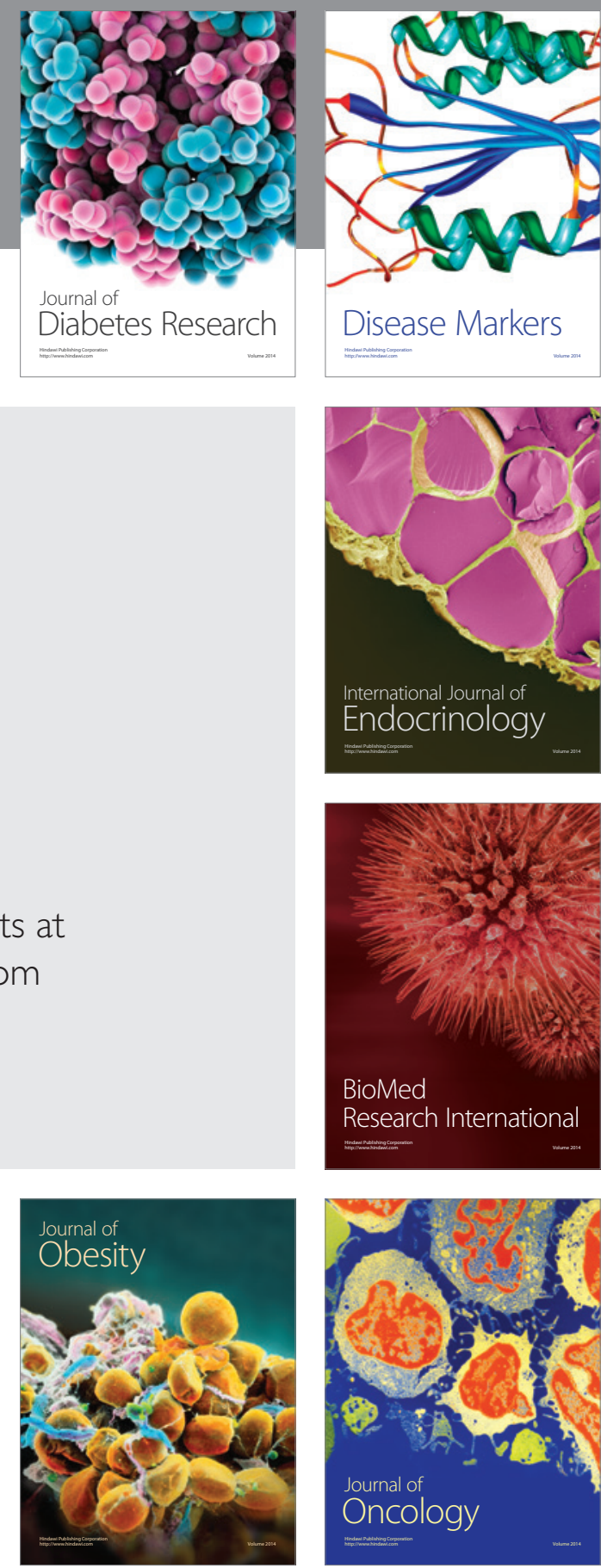

Disease Markers
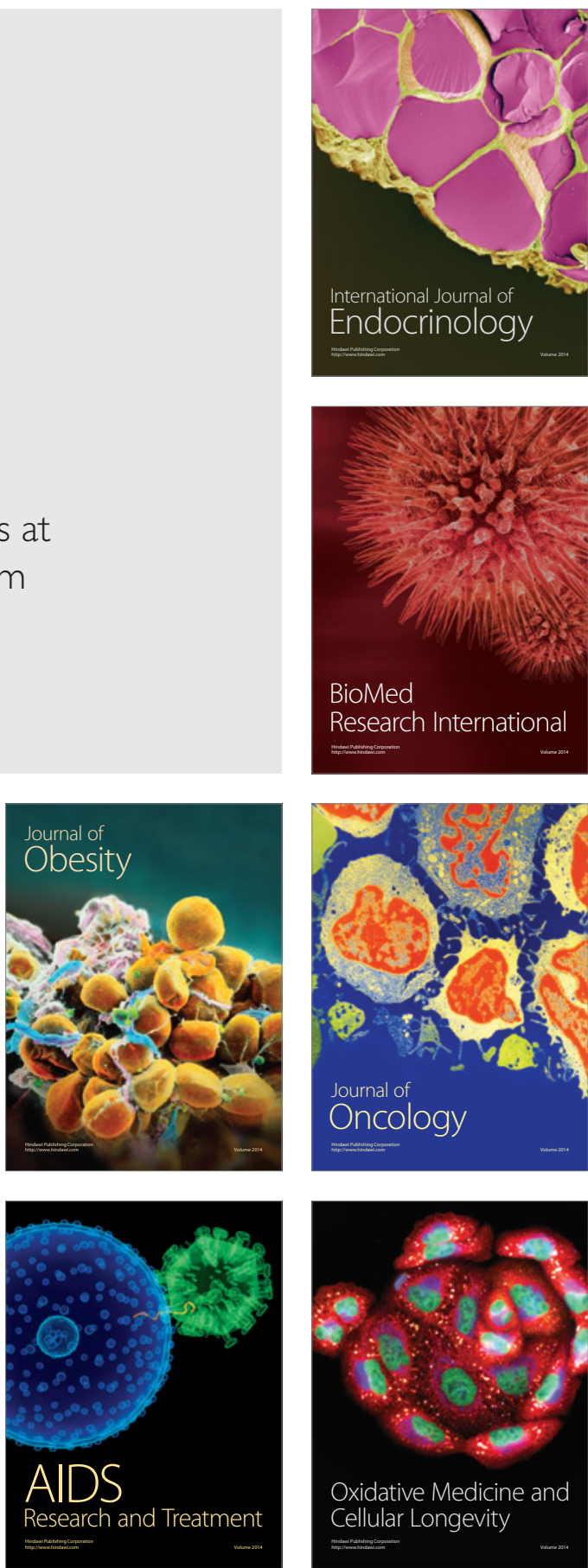